\title{
Isatin Derived Mixed Ligand Metal Complexes as Antimicrobial, Antioxidant Agents and Catalyst for Oxidation of Styrene
}

\author{
M. Vairalakshmi ${ }^{1,2^{*}}$ and S. Johnson Raja ${ }^{3}$
}

${ }^{1}$ Research \& Development Centre, Bharathiar University, Coimbatore, India

${ }^{2}$ Department of Chemistry, V.V. Vanniaperumal College for women, Virudhunagar, India

${ }^{3}$ Department of Chemistry, The American College, Madurai, India

*Corresponding author: lakshmichemist1988@gmail.com

\begin{abstract}
A novel series of mixed ligand transition metal complexes of $\mathrm{Cu}(\mathrm{II}), \mathrm{Zn}(\mathrm{II}), \mathrm{Ni}$ (II) and $\mathrm{Co}$ (II) have been synthesized from the Schiff base ligand, 3-(naphthalen-1-ylimino)indolin-2-one (achieved by the condensation of isatin and naphthylamine) and 1, 10-phenonthroline. The structural features were corroborated by means of elemental analyses, molar conductance, IR, UV-Vis, ${ }^{1} \mathrm{H}$ NMR and mass spectral studies. The data displays that these complexes have the composition of [MLX] type where $\mathrm{X}=$ 1, 10-phenonthroline. The UV-Vis. and magnetic susceptibility data of the complexes suggest a squareplanar geometry around the central metal ion. The IR spectral data of the ligand exhibits the presence of iminic group and its complexes manifest that the imine group of the Schiff base coordinate with the metal ion and decreased value of carbonyl group indicates which coordinate to the metal. The proton NMR spectrum of the ligand shows the presence of imine group. The mass spectral data also confirms the metal complexes as [MLX] type. Molar conductance values of the complexes have been found in the range of $5-14 \mathrm{ohm}^{-1} \mathrm{~cm}^{2} \mathrm{~mol}^{-1}$, suggesting the non-electrolytic nature of the complexes. The antimicrobial study reveals that copper and cobalt complexes are better antimicrobial agents than the standard drug streptomycin and Nystatin. The copper and cobalt complexes exhibit remarkable antioxidant potential than the other complexes. The catalytic oxidation of styrene by $\mathrm{H}_{2} \mathrm{O}_{2}$ was carried out in acetonitrile in the presence of mixed ligand metal complex as catalyst. The result of the catalytic study reveals that the zinc complex effectively catalyses the oxidation of styrene.
\end{abstract}

Keywords: Mixed ligand transition metal complexes, square-planar geometry, antimicrobial activity, potent antioxidant, oxidation of styrene. 
Heterocyclic compounds are widely distributed in nature and essential to many biochemical processes. These compounds have more attention for many reasons, chief among them are their biological activities. In recent decades, have seen the introduction of a number of pharmaceutical compounds which contain five, six, and seven-membered rings such as piperazines, piperidines, imidazoles, benzodiazepines and other heterocycles containing nitrogen, sulfur and oxygen. Compounds containing these heterocycles have important physiological properties ranging from anti-histamine, analgesic, anti-inflammatory, antihypertensive and anti-cancer. Especially Isatin(indole-2, 3-dione) and its derivatives have been shown to exhibit a wide range of biological activities ${ }^{[1]}$. Isatin based Schiff base copper(II) complex is related to the antiviral drug, methisazone. A significant rising interest in the design of metal compounds as drugs and diagnostic agents is currently observed in the area of scientific inquiry appropriately termed medicinal inorganic chemistry ${ }^{[2,3]}$. Isatin is an endogenous compound, widely distributed in mammalian tissues and body fluids ${ }^{[4,5]}$ and is pharmacological agent having a range of action in the brain. The synthesis of new Schiff bases and their transition metal complexes and investigation of their properties have been being a popular theme due to their strong coordination capability and diverse biological activities, such as antibacterial ${ }^{[6]}$, antifungal ${ }^{[7,8]}$, anti-proliferative activities ${ }^{[9]}$, anti-inflamatory activities ${ }^{[10]}$, antineoplastic ${ }^{[1]]}$ and anti-angiogenesis activities ${ }^{[12]}$ antiprotozoal ${ }^{[13]}$, antioxidant ${ }^{[14-16]}$ antitumor activities etc. ${ }^{[17]}$. In this regard, isatin based mixed-ligand metal complexes have been found to be particularly useful because of their potential application in modern medicine. The catalytic oxidation of alkenes furnishes an auspicious synthesis of carbonyl compounds. Hydrogen peroxide is an attractive oxidant ${ }^{[18]}$ because of its low cost and it degrades only to $\mathrm{O}_{2}$ and $\mathrm{H}_{2} \mathrm{O}$. Aromatic Schiff base metal complexes catalyse reactions on oxygenation ${ }^{[19,20]}$, hydrolysis ${ }^{[21]}$, electro-reduction ${ }^{[22]}$ and decomposition ${ }^{[23]}$. The use of $\mathrm{H}_{2} \mathrm{O}_{2}$ to oxidize styrene produces different products, depending upon the catalyst and the reaction conditions. The selective oxidation of styrene to acetophenone can be carried out by $\mathrm{H}_{2} \mathrm{O}_{2}$ in the presence of an appropriate metalbases catalyst to activate the oxidant.

Bearing the above evidences in mind, the synthesis of a heterocyclic Schiff base ligand and its $\mathrm{Cu}(\mathrm{II})$, $\mathrm{Zn}(\mathrm{II}), \mathrm{Ni}(\mathrm{II})$ and $\mathrm{Co}(\mathrm{II})$ complexes have been reported. The complexes of $\mathrm{Co}(\mathrm{II}), \mathrm{Ni}(\mathrm{II}), \mathrm{Cu}(\mathrm{II})$ and $\mathrm{Zn}$ (II)They have been characterized by UV-Vis., IR, ${ }^{1} \mathrm{H}$ NMR and ESI-mass studies in order to interrogate the coordination mode of ligand The antimicrobial and antioxidant property of the complexes have been investigated. Herein the selective catalytic oxidation of styrene using $\mathrm{H}_{2} \mathrm{O}_{2}$ as an oxidant was also carried out in the presence of synthesized metal complexes as catalyst.

\section{EXPERIMENTAL}

\section{Materials and methods}

All chemicals used in the present work, viz., isatin, naphthylamine, 1,10-phenanthroline, copper, zinc, nickel and cobalt chlorides were of analytical reagent grade (Merck, Germany). Common solvents like ethanol, methanol, chloroform, ether, acetone and DMSO used at various stages of this work were purified according to the standard procedures described in Weissenburg series ${ }^{[24]}$ and in quantitative analysis by Vogel ${ }^{[25]}$.

\section{Physical Measurements}

Elemental analysis (C, H and N) were performed using a Carlo Erba 1108 analyzer at the sophisticated 
analytical instrument facility (SAIF), Central Drug Research Institute (CDRI), Lucknow, India. The molar conductivity of the complexes $(0.001 \mathrm{M})$ in DMSO solution was measured using a Systronic Model-304 digital direct reading conductivity meter. The measurements of magnetic susceptibility were carried out by using the Gouy method at room temperature on powder sample of the complexes. Copper sulphate was used as calibrant. Infra-red spectra of the Schiff base and its metal complexes were recorded as $\mathrm{KBr}$ discs in the range of $400-4000 \mathrm{~cm}^{-1}$ on a Shimadzu spectrophotometer at Madurai Kamaraj University, Madurai. The electronic absorption spectra of the Schiff base and its metal complexes, $\mathrm{Cu}(\mathrm{II}), \mathrm{Zn}$ (II), $\mathrm{Ni}(\mathrm{II})$ and $\mathrm{Co}(\mathrm{II})$ in ethanol were recorded on a Shimadzu UV-1601 spectrophotometer. The $400 \mathrm{MHz}$ ${ }^{1} \mathrm{H}$ NMR spectra of the Schiff base and its zinc complex in $\mathrm{CDCl}_{3}$ were recorded at SAIF IIT Mumbai using tetramethylsilane as internal standard. Electrospray ionization (ESI) mass spectra of the samples were performed at the Sophisticated Analytical Instrument Facility, IIT Mumbai.

\section{Estimation of metal}

The metals were estimated gravimetrically as their oxides ${ }^{[26]}$ by fusion with AnalaR ammonium oxalate. In a typical experiment, about $0.3 \mathrm{~g}$ of the dried complex was accurately weighed in a previously weighed silica crucible. AnalaR ammonium oxalate, roughly three parts by weight of the complex, was added and the mixture was incinerated slowly at first and then strongly using a Bunsen burner for $3 \mathrm{~h}$. It was then cooled in a desiccator and weighed. The procedure was repeated till the final oxide weight was constant. From the weight, the percentage of metal in the complex was calculated.

\section{Synthesis}

\section{Synthesis of ligand (L)}

A methanolic solution of naphthylamine $(0.03 \mathrm{~mol}, 4.30 \mathrm{~g})$ was added to a methanolic solution of isatin $(0.03 \mathrm{~mol}, 4.41 \mathrm{~g})$ and the reaction mixture was refluxed for $c a .10 \mathrm{~h}$. The progress of the reaction was monitored by using TLC. The resulting yellowish orange precipitate was filtered and washed with methanol. Yield $=89 \%$. The schematic representation of the Schiff base formation is given in Fig. 1 .

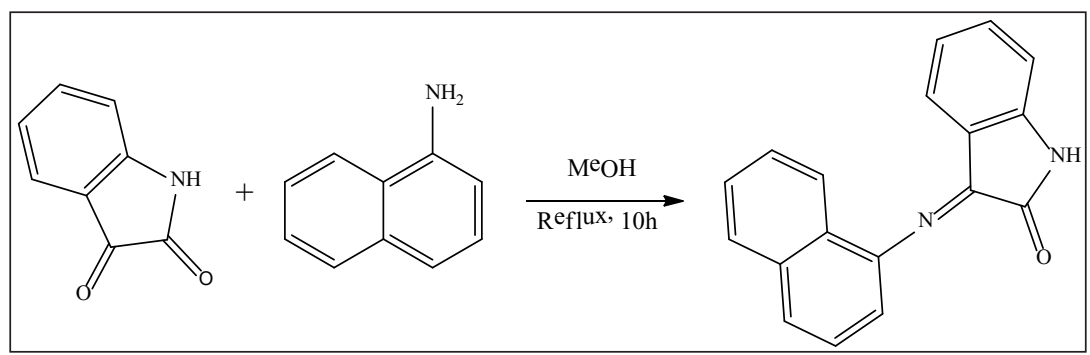

Fig. 1: Synthesis of the Schiff base

\section{Synthesis of $[\mathrm{MLX}]$ complexes}

The complexes were prepared by mixing the appropriate molar quantity of the above ligand and the metal(II) chlorides using the following procedure. A methanolic solution of Schiff base $(0.003 \mathrm{~mol}$, 
$0.817 \mathrm{~g}$ ) was added to the methanolic solution of metal chlorides [Cu(II), $\mathrm{Zn}(\mathrm{II}), \mathrm{Ni}(\mathrm{II})$ and $\mathrm{Co}(\mathrm{II})](0.003$ $\mathrm{mol})$ and refluxed for $4 \mathrm{hrs}$. To the above mixture, the methanolic solution of 1, 10-phenanthroline (0.003 mol, $0.541 \mathrm{~g}$ ) was added in a 1:1:1 molar ratio and refluxed for ca. $1 \mathrm{~h}$. The solid product obtained was filtered, washed with methanol and recrystalized from methanol.

\section{Biological Studies}

\section{Antibacterial Studies}

Antibacterial activity of Schiff base and its complexes were evaluated using disc diffusion concept of the Kirby-Bauer sensitivity test. Human pathogens such as Bacillus subtilis, Staphylococcus aureus, Escherichia coli and Proteus mirabilis are used in the current study. Nutrient agar was used as a basal medium for the culture of the test bacteria. The agar plates were then inoculated with broth cultures diluted to $0.5 \mathrm{McF}$ arland turbidity $\left(\sim 1.5 \times 10^{8}\right.$ cells $\left.\cdot \mathrm{mL}^{-1}\right)$. The stock solutions were prepared by dissolving the compounds in appropriate solvents (DMSO). Discs ( $5 \mathrm{~mm}$ diameter and $1 \mathrm{~mm}$ thickness) containing known amounts of an antimicrobial agent were placed on the surface of an agar plate that has been inoculated with a standardized suspension of microorganisms to be tested. Paper discs with only dimethylsulfoxide (DMSO) were used as negative controls. Then the plates were incubated at $37^{\circ} \mathrm{C}$ for $24 \mathrm{~h}$. During this period, the test solution diffused and affected the growth of the inoculated bacteria. The susceptibility of bacterial species was determined by the diameter of zone of inhibition (in millimeter) ${ }^{[27]}$. Streptomycin was used as standard.

\section{Antifungal Studies}

The in vitro antifungal screening of the Schiff base and its complexes were evaluated by the disc diffusion method $^{[28]}$ against the fungi such as Aspergillus niger, Aspergillus flavus, Rhizoctonia bataicola and Candida albicans. Potato dextrose agar was used as medium for evaluation of antifungal activity. For preparing the agar media, $200 \mathrm{~g}$ of potato extract, $20 \mathrm{~g}$ of agar and $20 \mathrm{~g}$ of dextrose were dissolved in 1000 $\mathrm{mL}$ of distilled water in a clean conical flask. The solution was boiled to dissolve the medium completely and sterilized by autoclaving at $15 \mathrm{psi}$ pressure $\left(120^{\circ} \mathrm{C}\right)$ for $30 \mathrm{~min}$. After sterilization, $20 \mathrm{~mL}$ of media was poured into the sterilized petri plates. These petri plates were kept at room temperature for some time. After few minutes the medium got solidified in the plates. Then, it was inoculated with microorganisms using sterile swabs. The $5 \mathrm{~mm}$ diameter and $1 \mathrm{~mm}$ thickness of the disc was filled with the test solution $(100 \mu \mathrm{g} / \mathrm{ml})$ using a micropipette and the plates were incubated at $37^{\circ} \mathrm{C}$ for $72 \mathrm{~h}$. During this period, the test solution diffused and affected the growth of the inoculated fungi. After $72 \mathrm{~h}$ of incubation at $37^{\circ} \mathrm{C}$, the diameter of the zone of inhibition was measured ${ }^{[27]}$. Nystatin was used as standard.

\section{Antioxidant Studies (DPPH assay)}

The evaluation of antioxidant activity of newly synthesized compounds was done by DPPH radical scavenging activity assay ${ }^{[29]}$. Different concentrations $(100,50,25,12.5 \mu \mathrm{g} / \mathrm{ml})$ of Schiff base metal complexes were weighed respectively and dissolved in DMSO. Then $5 \mathrm{ml}$ of $0.1 \mathrm{mM}$ methanolic solution of DPPH (1, 1, diphenyl - 2 - picrylhydrazyl) was added to each of the test tube containing the sample and the tubes were shaken vigorously. They were then allowed to stand at room temperature for 30 minutes. 
The control was prepared without any compound and methanol was used for base line corrections in absorbance (OD) of samples measured at $517 \mathrm{~nm}$. For each concentration, the decrease in the absorbance was recorded and percentage quenching of DPPH was calculated. The radical scavenging activities were expressed as \% scavenging activity and were calculated by the following formula:

$$
\% \text { Radical scavenging activity }=\frac{\text { Control OD }- \text { Sample OD }}{\text { Control OD }} \times 100
$$

\section{Catalytic activities}

The catalytic oxidation of styrene was carried out under vigorous stirring in a round-bottomed flask fitted with a Leibig condenser. A mixture of styrene $(0.05 \mathrm{~mol}, 5.73 \mathrm{ml})$, acetonitrile $(4.5 \mathrm{ml})$, hydrogen peroxide $(0.05 \mathrm{~mol}, 1.17 \mathrm{ml})$ and the metal complex $(0.5 \mathrm{mmol})$ as catalyst were introduced into the round-bottomed flask and heated at $60^{\circ} \mathrm{C}$ with constant stirring. The progress of the reaction of followed by using TLC by withdrawing an aliquots of the reaction mixture. The reaction mixture was cooled to room temperature after completion of the reaction. The product was then extracted with diethyl ether and washed with water. The ether layer was dried over anhydrous $\mathrm{MgSO}_{4}$. Under this controlled condition, the selective oxidation product acetophenone was afforded and purified by column chromatography.

\section{RESULTS AND DISCUSSION}

\section{Analytical Studies}

The mixed ligand metal complexes of the type [MLX] where, $\mathrm{M}=\mathrm{Cu}(\mathrm{II}), \mathrm{Zn}(\mathrm{II}), \mathrm{Ni}(\mathrm{II})$ and $\mathrm{Co}(\mathrm{II}), \mathrm{L}=$ bidentate Schiff base, $\mathrm{X}=1,10$-phenanthroline have been synthesized and characterized by spectral and analytical data. The elemental analyses for the metal complexes agree well with the calculated values showing that the complexes have 1:1 metal/ligand ratio. The low molar conductance value of the complexes in DMSO for $10^{-3} \mathrm{M}$ solutions at room temperature is consistent with non-electrolytes with no counter ions (chloride) in the complexes. The absence of chloride is evident from silver nitrate test ${ }^{[25]}$.

\section{Infrared Spectral studies}

The coordinating atoms were determined from IR spectra of the ligand and complexes. The IR spectrum of the free ligand (L) shows a broad band around $3199 \mathrm{~cm}^{-1}$ which can be assigned to $\mathrm{NH}$ stretching vibration of isatin moiety. The position of this band remains at nearly the same frequency in spectra of the metal complexes suggesting the uncoordination of this group. The band at $1753 \mathrm{~cm}^{-1}$ in the spectrum of the free ligand, assigned to $v_{\mathrm{C}=\mathrm{O}}$ of isatin moiety ${ }^{[30]}$, shifts towards lower values around $1735-1710 \mathrm{~cm}^{-1}$ indicating the coordination of the carbonyl oxygen atom of the isatin residue. The spectrum of the free Schiff base ligand shows the $-\mathrm{C}=\mathrm{N}$ band in the region $1659 \mathrm{~cm}^{-1}$, which is shifted to lower frequencies in the spectra of all the complexes $\left(1615-1606 \mathrm{~cm}^{-1}\right)$ indicating the involvement of $-\mathrm{C}=\mathrm{N}$ nitrogen in coordination to the metal ion ${ }^{[31]}$. The appearance of two new bands at the region $571-503 \mathrm{~cm}^{-1}$ and $424-417$ $\mathrm{cm}^{-1}$ in the spectra of the complexes, due to $v_{\mathrm{M}-\mathrm{N}}$ and $v_{\mathrm{M}-\mathrm{O}}$ stretching vibrations respectively also confirms the formation of metal complexes. 


\section{Electronic absorption Spectra and magnetic measurement}

The electronic absorption spectra of the ligand and its $\mathrm{Cu}$ (II), $\mathrm{Zn}$ (II), $\mathrm{Ni}$ (II) and $\mathrm{Co}$ (II) complexes were recorded at $300 \mathrm{~K}$ in ethanol. The ligand shows a band at $33670 \mathrm{~cm}^{-1}$ assigned for intra-ligand charge transfer transition. The electronic absorption spectrum of copper(II) complex in ethanol shows a band at $21184 \mathrm{~cm}^{-1}$ which can be assigned to ${ }^{2} \mathrm{~B}_{1} \mathrm{~g} \rightarrow{ }^{2} \mathrm{~A}_{1} \mathrm{~g}$ transition, reveals that the copper(II) complex exists in square-planar geometry ${ }^{[32]}$. The $\mathrm{Cu}(\mathrm{II})$ complex has magnetic moment value $1.69 \mathrm{BM}$ reveals square planar geometry around the metal ion[12]. Nickel (II) complex exhibits an absorption band at 17606 $\mathrm{cm}^{-1}$ assigned to a ${ }^{1} \mathrm{~A}_{1 \mathrm{~g}} \rightarrow{ }^{1} \mathrm{~B}_{\mathrm{gg}}$ transition and another band at $15699 \mathrm{~cm}^{-1}$ which can be attributed to a ${ }^{1} \mathrm{~A}_{1 \mathrm{~g}}$ $\rightarrow^{1} \mathrm{~A}_{2 \mathrm{~g}}$ transition which are coherent with square planar Ni(II) complex ${ }^{[33]}$. The diamagnetic nature of the $\mathrm{Ni}$ (II) complex further supports its square planar nature. Cobalt(II) complex shows an absorption bands at $22779 \mathrm{~cm}^{-1}$ and $19194 \mathrm{~cm}^{-1}$ assigned to ${ }^{2} \mathrm{~B}, \mathrm{~g} \rightarrow{ }^{4} \mathrm{~A} g(\mathrm{P})$ and to ${ }^{2} \mathrm{~B} \mathrm{~g} \rightarrow{ }^{4} \mathrm{Eg}(\mathrm{P})$ transitions, respectively, which suggests square planar geometry of the complex ${ }^{[32,34]}$. The magnetic moment value of 2.27 B.M also confirms the possibility of square planar geometry. Zn (II) complex does not exhibit d-d transition due to its diamagnetic nature. The electronic absorption spectrum of the ligand and its Copper complex are given in Fig. 2 and 3.

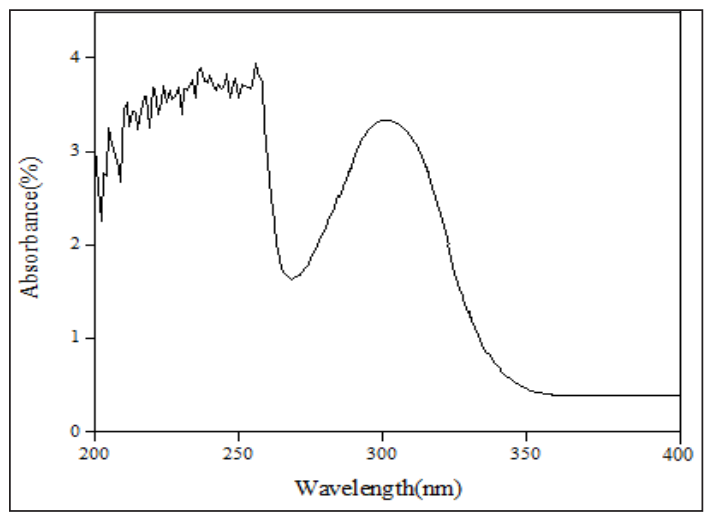

Fig. 2: UV Visible spectra of Ligand

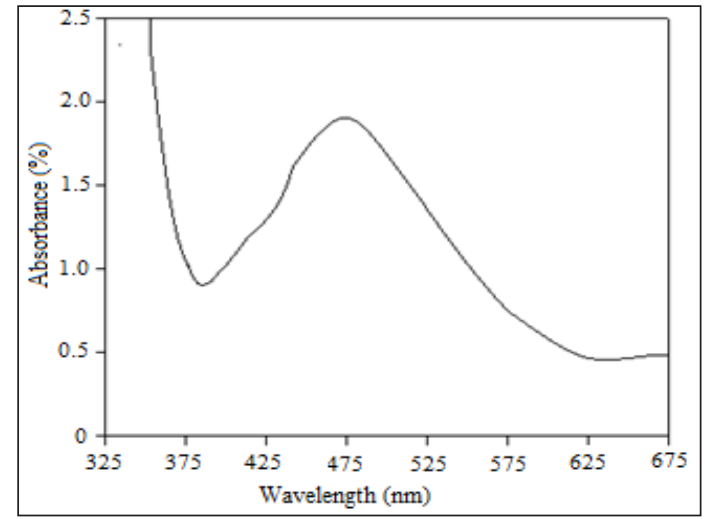

Fig. 3: UV Visible spectra of [CuLX]

\section{Proton Magnetic Resonance Spectra}

The ${ }^{1} \mathrm{H}-\mathrm{NMR}$ spectra of ligand and its zinc (II) complex was recorded in $\mathrm{CDCl}_{3}$. The ligand shows the signal at $10.72 \mathrm{ppm}$ is assigned to $\mathrm{NH}$ proton of isatin moiety and the multiplet signal around $6.42-7.06$ ppm is due to aromatic protons ${ }^{[35]}$. In addition to these, multiplet peak observed at 7.27-7.91 ppm is ascribed to naphthalene ring protons. In the ${ }^{1} \mathrm{H}$ NMR spectrum of $\mathrm{Zn}$ (II) complexes, the protons of $\mathrm{L}$ are shifted to down field due to the coordination to the metal ions. The resonance peaks observed in the spectrum of the $[\mathrm{ZnL}(\mathrm{X})]$ complex at 7.34 -7.40, 8.07-8.45 ppm are assigned to the 1,10-phenanthroline protons.

\section{Mass spectra}

The ESI - mass spectra of ligand and its Zn (II) complex show molecular ion peaks confirming the proposed formula. The mass spectrum of ligand $\left(\mathrm{C}_{18} \mathrm{H}_{12} \mathrm{~N}_{2} \mathrm{O}\right)$ shows a molecular ion peak m/z at 272 
which is equivalent to its molecular weight and also exhibits two additional peaks $\mathrm{m} / \mathrm{z}$ at 273 and 274 , which are corresponding to $(\mathrm{M}+1)$ and $(\mathrm{M}+2)$ peaks respectively. The elemental and analytical data of the zinc complex suggest its empirical formula as $\left[\mathrm{ZnC}_{30} \mathrm{H}_{20} \mathrm{~N}_{4} \mathrm{O}\right]$ and this is supported by the ESI mass spectrum. The highest peak at $518 \mathrm{~m} / \mathrm{z}$ value was observed, corresponding to the mass of the entire mononuclear complex and also exhibits one additional peak $\mathrm{m} / \mathrm{z}$ at 519 , which is corresponding to $(\mathrm{M}+1)$ peak. Apart from this, the spectrum shows few other peaks at m/z 127, 145 and 180 which are due to various fragments $\left[\mathrm{C}_{10} \mathrm{H}_{7}\right]^{+},\left[\mathrm{C}_{8} \mathrm{H}_{5} \mathrm{~N}_{2} \mathrm{O}\right]^{+}$and $\left[\mathrm{C}_{12} \mathrm{H}_{18} \mathrm{~N}_{2}\right]^{+}$respectively. By comparing all the analytical and spectral data of the complexes, it is evident that these are monomeric in nature. The proposed structure of the complexes is given in Fig. 4.

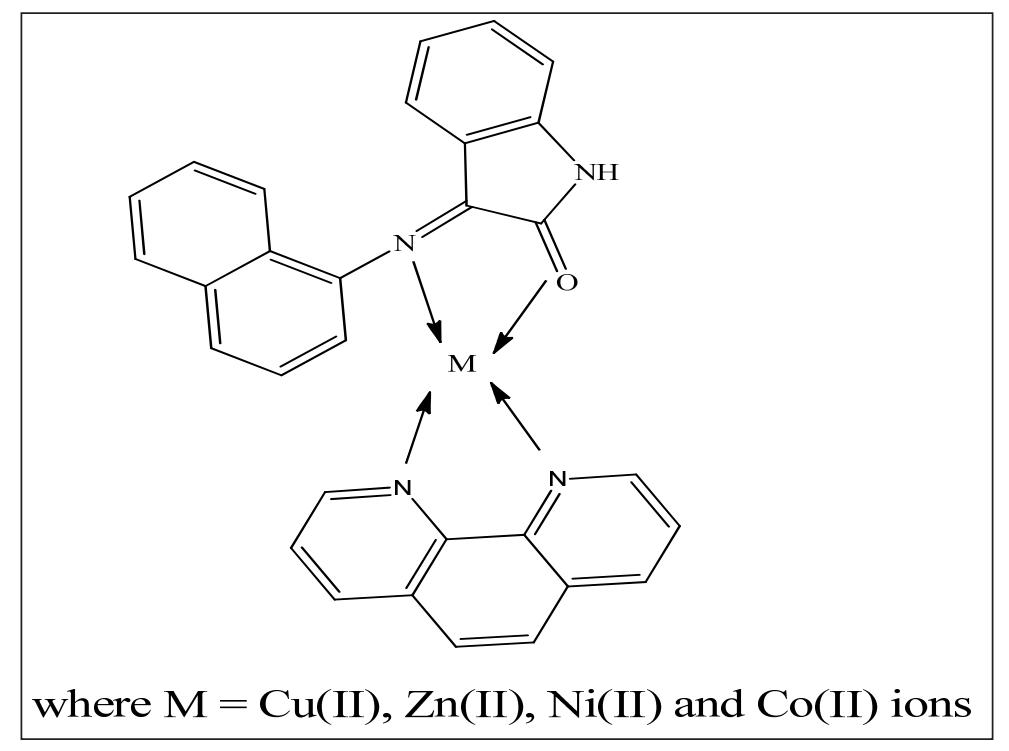

Fig. 4: Structure of synthesized complexes

\section{Antibacterial Studies}

The ligand, metal (II) complexes and standard drug Streptomycin were screened separately for their antibacterial activity against $B$. subtilis, S. aureus (gram positive) and E. coli, P. mirabilis gram negative). Three different concentrations $(25 \mu \mathrm{g} / \mathrm{ml}, 50 \mu \mathrm{g} / \mathrm{ml}, 75 \mu \mathrm{g} / \mathrm{ml})$ of the compounds have been tested for antibacterial assay. The zone of inhibition of the ligand and its complexes against the growth of bacteria was shown in Fig. 5. The activity of the ligand and its metal complexes has been compared with the activity of the standard antibiotic Streptomycin. It has been noticed that metal complexes have potent antibacterial activity than the free ligand. The activity has been increased with increasing the concentration of the complexes ${ }^{[36]}$. The antibacterial results suggest that the copper (II) and cobalt (II) complexes possess substantial antibacterial activity than the standard drug Streptomycin. The zinc (II) and nickel (II) complexes exhibit better activity against all the bacteria examined. The increase in antimicrobial activity of metal complexes may be explained on the basis of chelation theory. On chelation, the polarity of the metal ion will be reduced to a greater extent due to the overlap of the ligand orbital and partial sharing of the positive charge of the metal ion with donor groups ${ }^{[37]}$. Farther, the mode of action of compounds 
may involve in the formation of a hydrogen bond through the azomethine group with the active centre of cell constituents, resulting in interference with the normal cell process ${ }^{[38]}$.

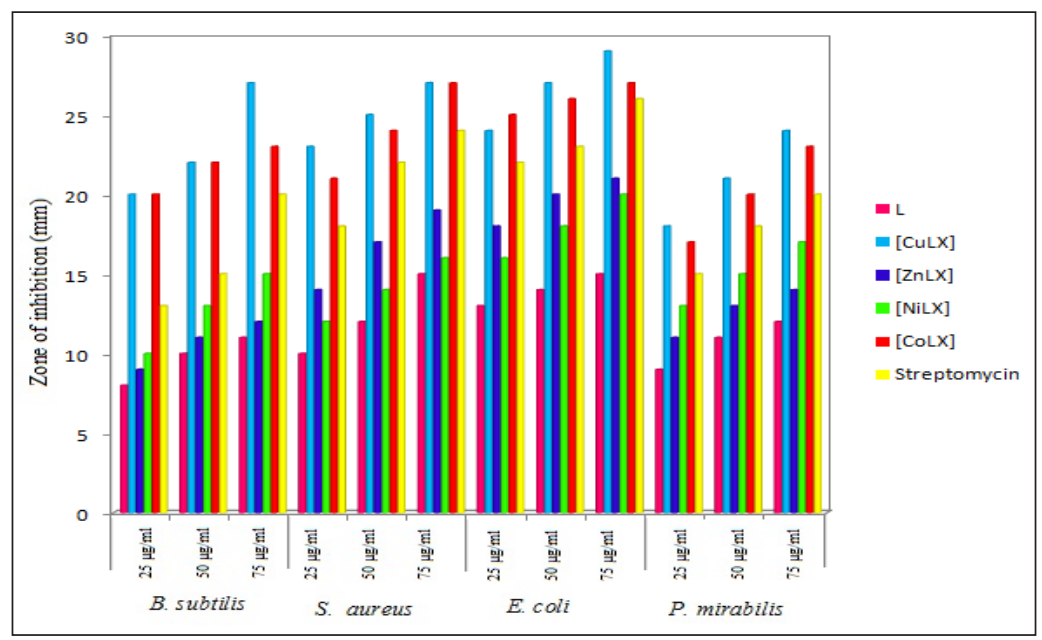

Fig. 5: Antibacterial activity of ligand L and its metal (II) complexes

\section{Antifungal Studies}

The antifungal data pointed out that the ligand and its $\mathrm{Cu}(\mathrm{II}), \mathrm{Zn}$ (II), Ni(II) and $\mathrm{Co}(\mathrm{II})$ complexes exhibit an perceptible activity against $A$. niger, A. flavus, R. bataicola and C. albicans at $100 \mu \mathrm{g} / \mathrm{ml}$ concentration. The zone of inhibition of the ligand and its complexes against the growth of fungai was shown in Table 1. The comparative analysis shows a higher antifungal activity for the metal complexes than the free ligands ${ }^{[39]}$. However, Copper (II) complex displays enhanced activity against all the fungal strains than the standard drug Nystatin. Cobalt (II) complex exhibits pronounced activity against $R$. bataicola and $C$. albicans than the standard drug but in case of A. niger and A. flavus it mimics Nystatin. This increased activity of the metal complexes may be due to the reduction in the polarity of the metal ion by partial sharing of the positive charge with the donor atoms of the ligand so that the electron is delocalized within the metal complex. This may increase the lipophilic and hydrophobic character of the metal complex, enabling it to penetrate the lipid layer of the organism and killing them more effectively ${ }^{[40]}$.

Table 1: Antifungal activity of ligand and its metal (II) complexes

\begin{tabular}{|ccccc|}
\hline \multirow{2}{*}{ Compound } & \multicolumn{5}{c|}{ Zone of inhibition in $\mathbf{~ m m}$} \\
\cline { 2 - 5 } & A. niger & A. flavus & R. bataicola & C. albicans \\
\hline L & 6 & 5 & 5 & 8 \\
{$[$ CuLX] } & 16 & 15 & 14 & 18 \\
{$[$ ZnLX $]$} & 7 & 8 & 6 & 10 \\
{$[$ NiLX] } & 9 & 6 & 7 & 9 \\
{$[$ CoLX $]$} & 14 & 12 & 14 & 17 \\
Nystatin & 14 & 12 & 13 & 16 \\
\hline
\end{tabular}




\section{Antioxidant Studies}

The synthesized mixed ligand complexes were screened for their antioxidant activity. DPPH assay was performed to measure the capacity of the complexes to scavenge the DPPH free radicals. The colour change from purple to yellow produced by free radical scavenging, results a change in absorbance. Figure 6 shows the correlative effect of metal complexes on DPPH radical. Among all the complexes, copper and cobalt complexes revealed remarkable antioxidant activity. The zinc complex produced the better activity than the nickel complex. The order of scavenging activity of these complexes is as $\mathrm{Cu}>\mathrm{Co}>$ $\mathrm{Zn}>\mathrm{Ni}$. The increased antioxidant activity of the complexes can be ascribed to the electron withdrawing effect of the metal ions which assist the progress of the release of hydrogen to reduce the DPPH radical.

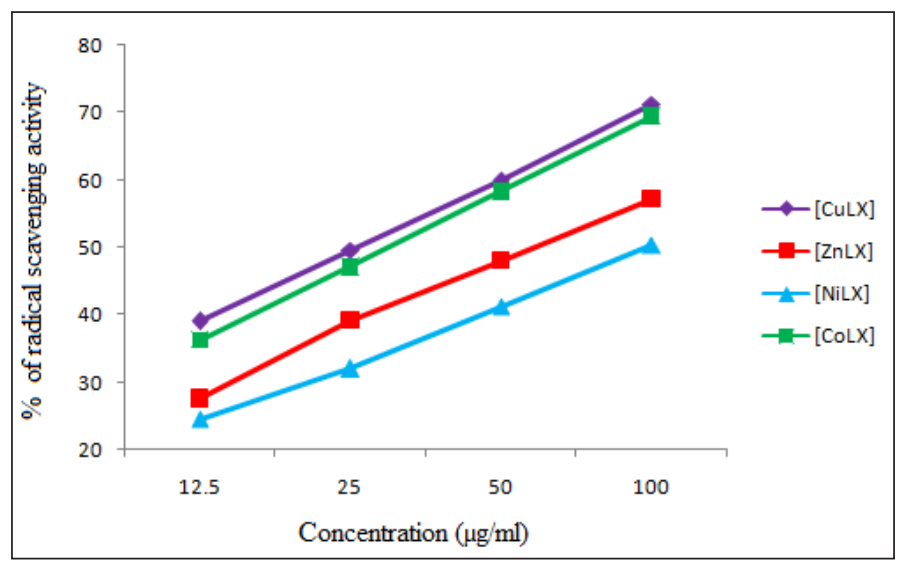

Fig. 6: Antioxidant activity metal (II) complexes

\section{Catalytic activities}

The selective oxidation of styrene with $\mathrm{H}_{2} \mathrm{O}_{2}$ in the presence of mixed ligand metal complexes was executed in acetonitrile medium. By a lot of trial errors, the selective oxidation of styrene to acetophenone in maximum yield was attained. Under the same experimental conditions, without [MLX] results only in less than $7 \%$ acetophenone formation. Among the synthesized mixed ligand metal complexes, zinc(II) complex afforded promising catalytic performance than the other complexes. The results are given in table 2.

Table 2: Catalytic Oxidation of styrene by [MLX]

\begin{tabular}{cc}
\hline \multirow{2}{*}{ Compound } & Product (\% yield) \\
\cline { 2 - 2 } & Acetophenone \\
\hline$[\mathrm{CuLX}]$ & 67 \\
{$[\mathrm{ZnLX}]$} & 85 \\
{$[\mathrm{NiLX}]$} & 54 \\
{$[\mathrm{CoLX}]$} & 60 \\
\hline
\end{tabular}

\{Reaction conditions: styrene $(0.05 \mathrm{~mol}, 5.73 \mathrm{ml})$; acetonitrile $(4.5 \mathrm{ml})$; hydrogen peroxide $(0.05 \mathrm{~mol}, 1.17 \mathrm{ml})$; [MLX] $(0.5 \mathrm{mmol})$; temperature $\left(60^{\circ} \mathrm{C}\right)$; time $\left.(22 \mathrm{~h})\right\}$ 


\section{CONCLUSION}

The mixed ligand complexes of $\mathrm{Co}(\mathrm{II}), \mathrm{Ni}(\mathrm{II}), \mathrm{Cu}(\mathrm{II})$ and $\mathrm{Zn}$ (II) with 3-(naphthalen-1-yl-imino)indolin2-one and 1,10-phenanthroline were synthesized. The structure of the complexes was confirmed by the elemental analyses, molar conductance, IR, UV-Vis., ${ }^{1} \mathrm{H}$ NMR and ESI mass spectral analysis. The analytical data and mass spectra of the ligand and the complexes confirm the stoichiometry of metal complexes as being of the [MLX] type. The electronic spectra and magnetic moment values of the complexes confirm the square-planar geometry. The low molar conductance value of the complexes in DMSO for $10^{-3} \mathrm{M}$ solutions at room temperature is consistent with non-electrolytes with no counter ions (chloride) in the complexes. The copper(II) and cobalt(II) complexes showed more potent antimicrobial activity against the microorganisms examined. All the complexes exhibited high radical scavenging activity. The order of scavenging activity of the complexes is as $\mathrm{Cu}>\mathrm{Co}>\mathrm{Zn}>\mathrm{Ni}$. The complexes have been tested for the catalytic activity in the selective oxidation reaction of styrene to acetophenone in the presence of hydrogen peroxide as oxidant. It is inferred that the zinc complex effectively catalyses the oxidation of styrene.

\section{ACKNOWLEDGEMENTS}

The authors express their thanks to the Bharathiar University for the approval of research programme. The authors sincerely acknowledge their thanks to the Management, Principal of V.V. Vanniaperumal College for Women for their keen interest and constant encouragement throughout this investigation.

\section{REFERENCES}

1. Pandeya, S.N., Siram, D., Nath, G. and Declercq, E. 1999. Synthesis, antibacterial, antifungal and antiHIV activities of Schiff and Mannich bases derived from isatin derivatives and $\mathrm{N}$-[4-(4'- chlorophenyl) thiazol-2-yl] thiosemicarbazide, Eur. J. Pharm. Sci., 9: 25- 31.

2. Issa, R.M., Azim, S.A., Khedr A.M. and Draz, D.F. 2009. Synthesis, characterization, thermal, and antimicrobial studies of binuclearmetal complexes of sulfa-guanidine Schiff bases, J. Coord. Chem., 62: $1859-1870$.

3. Cerchiaro, G., Aquilano, K., Filomeni, G., Rotilio, G., Ciriolo, M.R. and Ferreira, A.M.D.C. 2005. Isatin-Schiff base copper(II) complexes and their influence on cellular viability, J. Inorg. Biochem., 99: 1433-1440.

4. Guo, Y. and Chen, F. 1986. Synthesis, Characterization and Biological Activities of Isocoumarins, Triazoles, Thiadiazoles and Indolinones, Zhongcaoyao, 17(8): (CA104:213068f)

5. Medvedev A.E, Clow, A. and Sandler, M. et al. 1996. Isatin - a link between natriuretic peptides and monoamines? Biochem. Pharmacol., 52: 385-91.

6. Nazirkar, B., Mandewale, M. and Yamgar, R. 2019. Synthesis, characterization and antibacterial activity of $\mathrm{Cu}(\mathrm{II})$ and $\mathrm{Zn}$ (II) complexes of 5-aminobenzofuran-2-carboxylate Schiff base ligands, J. Taibah Univ. Sci., 13: 440-449. 
7. Vasanthi, R., Shyam Sundar, P., Ramana, H., Rao. K.N.V. 2017. Synthesis, Characterization And Antimicrobial Evaluation Of Some Novel 3-Hydrazone-1hbenzoindol-2(3h)-Ones, IAJPS., 4(2017): 3859-3863.

8. Pandeya, S.N., Sriram, D., Nath, G. and De Clercq, E. 1999. Synthesis, antibacterial, antifungal and anti-HIV evaluation of Schiff and Mannich bases of isatin derivatives with 3-amino-2- methylmercapto quinazolin-4(3H)-one, Pharm. Acta Helv., 74: 11-17.

9. Vine, K.L., Matesic, L., Locke, J.M. and Skropeta, D. 2013. Recent Highlights in the Development of Isatin-Based Anticancer Agents. In Advances in Anticancer Agents in Medicinal Chemistry; Bentham Science: Oak Park, IL, USA., 2: 254-312.

10. Sridhar, S.K. and Ramesh, A. 2001. Synthesis and pharmacological activities of hydrazones, Schiff and mannich bases of isatin derivatives. Biol. Pharm. Bull., 24: 1149-1152.

11. Karali, N. 2002. Synthesis and primary cytotoxicity evaluation of new 5-nitroindole-2,3-dione derivatives. Eur. J Med. Chem., 37: 909-918.

12. Evdokimov, N.M., Magedov, I.V., McBrayer, D. and Kornienko, A. 2016. Isatin derivatives with activity against apoptosis-resistant cancer cells, Bioorg. Med. Chem. Lett., 26: 1558- 1560.

13. Saranyaa, K., Santha Lakshmia, S., Mahadevia, P. and Logesh, G. 2015. Ternary transition metal complexes of tridentate (ONO) Schiff base: Synthesis, spectroscopic and biological studies, J. Chem. Pharm Res., 7: $851-858$.

14. Vijay Kumar, H. and Nagaraja Naik, 2010. Synthesis and antioxidant properties of some novel 5Hdibenz[b,f]azepine derivatives in different in vitro model systems. Eur. J. Med. Chem., 45: 2-10.

15. Vijay Kumar, H., Kishor Kumar, C. and Nagaraja Naik, 2011. Synthesis of novel 3-chloro-1-(5H- dibenz [b,f]azepine-5yl)propan-1-one derivatives with antioxidant activity. Med. Chem. Res., 20: 101-108.

16. Nagaraja Naik, Vijay Kumar, H. and Vidyashree, P.B. 2011. Synthesis and evaluation of antioxidant potential of novel isatin analogues. J. Pharm. Res., 4: 2686-2689.

17. Hossain, S., Zakaria. C. and Zahan, K.E. 2017. Structural and Biological Activity Studies on Metal Complexes Containing Thiosemicarbazone and Isatin based Schiff Base: A Review, Asian J. Research Chem., 10: 1-13.

18. Noyori, R., Aoki, M. and Sato, K. 2003. Green oxidation with aqueous hydrogen peroxide, Chem. Commun., 16: 1977-1986.

19. Nishinaga, A., Yamada, T., Fujisawa, H. and Ishizaki, K. 1988. Catalysis of cobalt-Schiff base complexes in oxygenation of alkenes: on the mechanism of ketonization, J. Mol. Catal., 48: 249 -264.

20. Xi, Z., Liu, W., Cao, G., Du, W., Huang, J., Cai, K. and Guo, H. 1986. Catalytic oxidation of naphthol by metalloporphyrins, Cuihau Xuebao, 7: 357- 363.

21. Chakraborty, H., Paul, N. and Rahman, M.L. 1994. Catalytic activities of Schiff bases aqua complexes of $\mathrm{Cu}(\mathrm{II})$ in the hydrolysis of amino acid esters, Trans. Met. Chem., 19: 524-526. 
22. Zhao, Y.D., Pang, D.W., Zong, Z., Cheng, J.K., Luo, Z.F., Feng, C.J., Shen, H.Y. and Zhungf, X.C. 1988. Electochemical studies of antitumor drugs, fundamental electrochemical characteristics of an iron(III) Schiff base complex and its interaction with DNA, Huaxe Xuebao., 56: 178-183.

23. Sreekala, R., Yusuff, K.K. and Mohammed. 1994. Catalytic activity of mixed ligand five coordinate Co (II) complexes of a polymer bound Schiff base, Catal (Pap Natl Symp), pp. 507-510.

24. Weissenberger, A., Proskauer, E.S., Riddick, J.A. and Toops, E.E. 1955. Organic Solvents: Physical Properties and Methods of Purification, Techniques of Organic Chemistry, $3^{\text {rd }}$ edn., Interscience, New York, 1955.

25. Vogel, A.I. 1989. Practical Organic Chemistry, $5^{\text {th }}$ edn., Longmann.

26. Angellici, R.J. 1969. Synthesis and Techniques in Inorganic Chemistry, W.B. Saunders Company.

27. Pelczar, M.J., Chan, E.C.S. and Krieg, N.R. 1998. Microbiology, $5^{\text {th }}$ edn, New York.

28. Kannan, N. 1996. Laboratory Manual in Microbiology, $1^{\text {st }}$ edn, Palani Paramount Publication, Palani.

29. Blois, M.S. 1958. Antioxidant Determinations by the Use of a Stable Free Radical, Nature, 26: 1199-1200.

30. Prasad, R.L., Kushwaha, A., Suchita; Kumar, M. and Yadav, R.A. 2008. Infrared and ab initio studies of conducting molecules: 2,5-Diamino-3,6-dichloro-1,4-benzoquinone. Spectrochim. Acta A Mol. Biomol. Spectrosc., 69: 304-311.

31. Vairalakshmi, M., Princes, R., Kokila Rani, B. and Johnson Raja, S. 2018. Synthesis, Structural Elucidation, Catalytic, Antibacterial and Antioxidant activity of thiophene derived mixed ligand metal complexes, $J$. Chil. Chem. Soc., 63: 3844-3849.

32. Lever A.B.P. 1968. Inorganic Electronic Spectroscopy, Elsevier, Amsterdam.

33. Bibhesh, K., Jagdish, C. and Hament, K. 2017. Pinkee, Spectral, Kinetics of Thermal Decomposition and Computational Analysis of Bioactive Metal Complexes of 4 -Methoxysalicyldeoxime, Inter. J. Applied Chem., 13: 235-253.

34. Nakamoto K. and McCarthy S.J. 1968. Spectroscopy \& Structure of Metal Chelate Compounds, John Wiley \& Sons, USA.

35. Raman, N. and Sobha, S. 2010. Synthesis, characterization, DNA interaction and antimicrobial screening of isatin-based polypyridyl mixed-ligand $\mathrm{Cu}(\mathrm{II})$ and Zn(II) complexes, J. Serb. Chem. Soc., 75: 773-788.

36. Wahab, Z.H. and Sarrag, M.R. 2004. Derivatives of phosphate Schiff base transition metal complexes: Synthesis, studies and biological activity. Spectro chim Acta., 60: 271-277.

37. Rehman, S.U., Chohan, Z.H., Gulnaz, F. and Supuran, C.T. In-vitro antibacterial, antifungal and cytotoxic activities of some coumarins and their metal complexes. J. Enzyme Inhib. Med. Chem., 20: 333-340.

38. Dharmaraj, N., Viswanathamurthi, P. and Natarajan, K. 2001. Ruthenium(II) complexes containing identate Schiff bases and their antifungal activity. Transition Met. Chem., 26: 105- 109. 
39. Nagar, R. 1990. Syntheses, characterization, and microbial activity of some transition metal complexes involving potentially active $\mathrm{O}$ and $\mathrm{N}$ donor heterocyclic ligands. J. Inorg. Biochem., 40: 349-356.

40. Amah, C., Ondoh, A.M., Yufanyi, D.M. and Gaelle, D.S.Y. 2015. Synthesis, crystal structure and antimicrobial properties of an anhydrous copper(ii) complex of pyridine-2-carboxylic acid. Inter. J. Chem., 7: 10-20. 
